Marie-Therese FALLAST

Sanela PANSINGER

Gerald KREBS

Martin MOSER

Andreas ZOBL

\title{
Systematically retrofitting city streets: Meeting the demands of climate change through multifunctional climate-responsive street gardens
}

The reintroduction of green infrastructure is a recognized approach to mitigating heat islands and flash floods in urban areas. Depending on its type and extent, green infrastructure (GI) can reduce local urban temperatures significantly and at the same time reduce the risk of flooding. This article views the streetscape as an important area of activity for GI-based climate-adaptation interventions for two main reasons: it serves as a conduit for urban human activity and mobility, and it acts as a significant heat store. The approach proposed unites some key elements that can form the basis for all future public-realm (streetscape) design, promoting a truly climate-responsive urban environment. These include reduction of sealing to only essential areas, decentralized water management using rain-garden technology, low maintenance, aesthetic planting supporting biodiversity, and sensor-based monitoring of thermal comfort parameters to optimize measures. It utilizes low-cost sensors for obtaining thermal comfort data to locate urban heat islands. It also proposes a GIS-based decision tool bringing together relevant data sets: temperature, level of surface sealing, and flood risk, as well as aspects such as the location of services, traffic, and urban planning. A pilot application as part of an ongoing Austrian government-funded climate adaptation project is described in which this methodology has been applied.

Keywords: public space, climate change, stormwater management, street drainage, sensor technology and digitization 


\section{Introduction}

Combating the effects of climate change in urban areas is a continuing challenge for cities and towns throughout Europe and the rest of the world. Decision-makers are faced with unpredictable weather situations that cause urban heat islands (UHIs) and flash floods, with an ensuing socioeconomic burden. The climate-change effects are exacerbated by the nature of the urban environment, with high built density and proliferation of impermeable surfaces that not only store heat but disrupt the natural water cycle. This not only results in reduced thermal comfort, particularly in city centres, but also in an increasing burden on sewer networks, often resulting in pollution at times of peak flows, which spill into natural water courses.

In seeking ways to deal with these diametrically opposed climate conditions, green infrastructure interventions are considered a sustainable alternative to ameliorate the problem and improve urban micro-climates. Although "greening our cities" has become a buzzword for more liveable urbanity in the twenty-first century, little progress has been made to systemize and optimize such interventions with the aim of improving their long-term efficacy and return on investment. This may be due in part to the inherent complexity of this multi-layered problem, which demands coordinated interplay between many stakeholders, especially with regard to the rigid planning tools and processes employed.

This article proposes a multifunctional approach that could contribute to best practice for more systematic incorporation of green infrastructure (GI) into the urban fabric. The approach specifically addresses significant UHI contributors by identifying problem areas using mobile sensors. Impermeable horizontal surfaces in the urban space, with no perceivable traffic function (dead zones), are targeted for unsealing and retrofitting with GI based on rain-garden technology in a way that recognizes its importance and function as an urban design element. With this approach, the causes of UHI may be tackled directly and sustainably while simultaneously promoting more positive and direct human interaction with nature and improving biodiversity within the city environment.

To achieve the proposed level of multifunctionality, a research consortium was established as a working group under the name Climate-Responsive Street Garden (ARGE - CRG), drawing its expertise from various fields, including landscape planning, hydrology, urban and spatial planning, traffic planning, IT (sensor and app development), and ecology. By actively pursuing an emphatically multidisciplinary approach to developing improvement measures in combating climate change, we seek to produce truly sustainable solutions for a multifac- eted problem. This means innovation in terms of both the multifunctional approach to the resulting urban GI and the transdisciplinary development and application of the method.

\subsection{The significance of street space}

The scope for action is most restricted in areas often most affected by UHIs and flash floods. Particularly in urban centres, the competition for ever-decreasing urban space means that a large proportion of surfaces are sealed, resulting in the loss of natural soil function and the ability to cool. Although GI is a highly sustainable form of climate-change amelioration, there is not an insignificant need for space. This requires designers to examine the street space more critically to prioritize and reassign function. Where is the need for action most pressing? Which type of green infrastructure should be prioritized where? Against this backdrop, cities and towns wish to maximize the positive effects of the investment and minimize negative aspects, which leads to requirements for appropriate decision tools and the need to promote multifunctionality (Monteiro et al., 2020).

There has been much discussion about the possibilities of space-saving vertical greening of facades as a possible alternative to climate-proof cities. Although they can make a valuable contribution, they do have some drawbacks (Manso et al., 2015). In an established city structure with a historical city centre protected by legislation to retain a specific cultural and identity-creating heritage, the options for green infrastructure such as vertical or roof gardens are diminished (Pansinger \& Förster, 2018). Until appropriate technology is developed in keeping with historic preservation requirements, alternative approaches are needed. A literature review shows that climate resilience mainly deals with larger systems, whereas the field is still developing at the building level (Kristl et al., 2020). Significantly, one square meter of green roof area is sufficient to evaporate two litres of water per day and bind ten grams of fine dust per year as well as absorb 375 grams of $\mathrm{CO}_{2}$. Green roofs also reduce street noise and contribute to energy savings of buildings (Willenbrock, 2020). In addition, a greener urban environment is generally perceived as more pleasant and thus contributes to the quality of the urban ambience (Kozamernik et al., 2020). The drive to promote active mobility and the quality of the public realm in recent times (Markvica et al., 2020) demands a rethink about how street space is organized. Pedestrians and cyclists experience their environment much more acutely than those using public transport or cars. The makeup of the "urban plinth" has been described as an important factor in making towns and cities attractive and liveable (Gehl, 2015). High ambient temperatures (i.e., UHIs) are also likely to dissuade active mobility and affect the quality of public space for healthy and infirm city-dwellers alike. In the 
future it is not only necessary to make cities interesting and attractive; they must mitigate climate change as well.

\subsection{Prioritizing multifunctional green interventions on the ground}

City heat maps show that horizontal surfaces in urban areas (Figure 1) such as roofs and roads are often most exposed to solar energy and contribute significantly to urban heat storage potential. Efforts have been made to increase the uptake of green roof technology with various forms of subsidies (Internet 1). This may support uptake, but it is rather ad hoc in its application. The grants available take no account of location or in-situ ambient conditions, and this type of GI is currently not suitable for retrofitting pitched roofs or those with historical relevance. The same may be said for vertical greening. A further hindrance is that green roofs require private initiative. Decisions by private owners to pay for such measures are primarily influenced by financial considerations. Unless there is a financial imperative or advantage, the uptake for such technology will remain low. It must be asked whether such an approach corresponds to the optimum and effective investment in GI as a climate amelioration measure. Why do municipalities not adopt a policy aimed at "harvesting the low-hanging fruit first"? Roads and many parking areas are generally under municipal control and account for a significant proportion of heat storage in urban areas. Consequently, implementing climate-change measures on municipally owned streets is not as fraught with obstacles as is the case for greening privately owned buildings. At the same time, they are conduits for all urban mobility - including pedestrians and cyclists. Regarding the attractiveness of cities at the human scale, it has been established that the makeup of the "urban plinth" is significant (Gehl, 2015). The occurrence of UHIs is an additional factor for reducing the appeal of urban areas. It is therefore imperative to deal with this aspect where it originates: in the street space. Ultimately, the aim must be to reduce the asphalt and concrete surface (heat storage) in these areas while allowing adequate mobility and quality of life for the urban population, improving liveability and sustainability. This process is an opportunity to make cities smarter, greener, and healthier, where there is a balance between energy and function, environment and aesthetics, and technology and nature, where people and their needs are foregrounded, and where the previous two-dimensional street is transformed (Pansinger, 2018). It is therefore logical to prioritize this part of the urban fabric as an initial step in implementing climate-adaptation measures.

It is therefore necessary to revisit urban space to identify opportunities that may have previously been overlooked. In urban areas a multitude of factors - in addition to lack of available space, also increased ground sealing, high traffic volumes, and

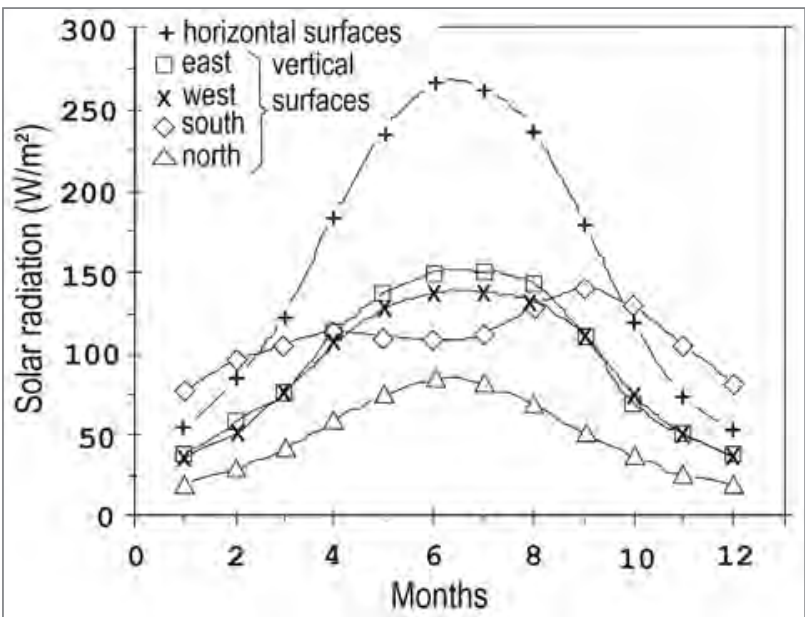

Figure 1: Total solar radiation on horizontal and vertical surfaces with various orientations in Istanbul (source: Kaynakli, 2011).

below-surface services - stand in the way of introducing larger-scale green areas. Consequently, the demand for smaller and more flexible solutions increases (e.g., parklets or mobile trees) constituting a type of "green acupuncture". This translates into small interventions with the potential to release new energy flows within urban space - in line with the concept of a "double archipelago" of disconnected urban islands and isolated green spaces constituting the city (Christiaanse, 2018: 45).

The contribution that high-quality urban green space can make to the intense discourse on the worrying decline in biodiversity (IPBES, 2019) on a global scale should be considered as a vehicle both to improve actual biodiversity in cities and to mobilize citizens by bringing the problem into sharper focus. This can be achieved by paying particular attention to the quality and not just the quantity of green infrastructure. The IPBES report (IPBES, 2019) highlights the importance of "nature-based solutions, healthy urban environments, improved access to green spaces, and ecological connectivity within urban spaces." In contrast to current monoculture-style urban planting, species-rich planting schemes, which draw predominately from native varieties, can have a profound and lasting positive effect on urban ecology. These include increased robustness against disease and a reduced requirement for fertilizers and pesticides (Isbell et al., 2017). Consequently, the knock-on effect is that insects and other pollinators can make an unhindered return, providing insight into the workings of nature. The experience has shown that the adoption of such diverse plantings results in a marked increase in the number and volume of insect varieties (Mody et al., 2020) and this can be noticed by the public. Thus, the opportunity presents itself to promote the message to the public that biodiversity in general is not only the foundation of humanity's continued existence but also underpins a worthwhile living environment in the urban context. 


\section{Method}

The previous section described the elements to be integrated into the climate-responsive street garden system. It has been recognized that decisions about how, where, and what GI intervention to introduce need to be formalized in a systemized procedure (Koc et al., 2018). Competing demands for space (e.g., traffic, people, services, etc.) must be reflected in the data structure and content of the problem space, and ultimately in the resulting tool. The complexity demands making decisions about the necessity of GI interventions based on the viability of implementing the measures. Some agencies and cities have made efforts to generate tools that assist in selecting pilot projects based on community involvement or demonstrate the shared benefits brought about by green interventions (e.g., Internet 2). These approaches consider two or three aspects or functions but fall short of the requirements to make an objective selection based on localized conditions and the spatial framework where the measures are to be implemented.

Currently, thermal comfort data are collected using remote sensing, aerial infrared photography, and/or satellite images (Xuexiu et al., 2020). Drone technology (Soto-Estrada et al., 2017) has also been successfully implemented to collect data related to urban temperature. These data sets are used to generate and calibrate urban climate models. The limitations of these approaches are twofold. Whether carried out using drones or otherwise, aerial photography provides only a snapshot of the situation. Localized climate conditions vary continually over time and situation. The inherent dynamic is not accounted for in this method. The behaviour of thermal conditions over longer periods of time would facilitate a more refined approach to introducing measures and allow monitoring of the effects after introducing those measures. The entry point for this approach is based on a five-dimensional model that demonstrates the versatility of green spaces and reflects the present and future needs of city dwellers (Figure 2). This model reflects the green infrastructure planning principles set out by Monteiro et al. (2020).

Against this background, a systematic and reproducible approach has been developed, referred to in this article as climate-responsive street gardens. The main aim is to optimize the process and result of introducing green infrastructure into urban areas by setting up a systematic and reproducible approach. The core elements of the system are identified and combined to ensure a high degree of multifunctionality. It is hoped that the proposed method will provide the foundation for future design interventions, guaranteeing the inclusion of climate adaptation measures in public realm design. This in turn ensures maximum functionality, in addition to aesthetic

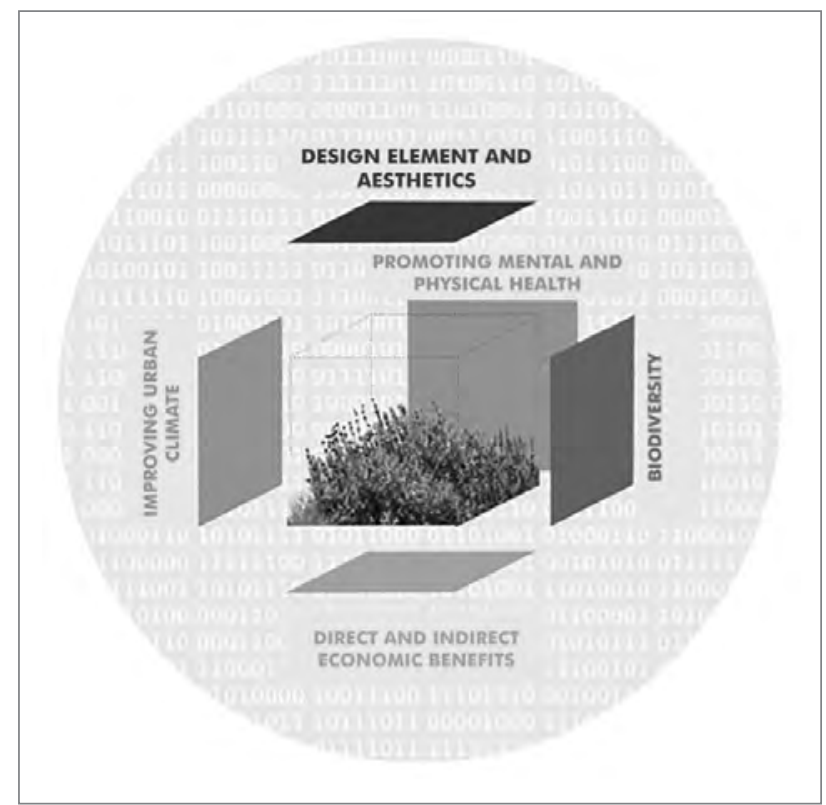

Figure 2: A five-dimensional application model (source: authors).

considerations, primarily for retrofitting existing urban structure but also for new construction.

The procedure adopted to achieve this aim includes the following aspects:

- Urban planning analysis and the identification of possible fields of action in relation to existing and planned spatial organization based on GIS data, aerial photographs, and planning instruments.

- The development of a low-cost method for collecting thermal comfort data (ambient temperature and humidity). The thermal comfort data will be used to ascertain where GI climate adaptation measures are required and are part of the input for the GIS decision tool. In addition, the data allow continuous post-implementation monitoring of effectiveness.

- The design of a decision tool based on a suitability assessment model that docks onto existing technology and brings together previous data sets (e.g., utility plans, traffic volumes, vegetation maps, legislation, and spatial models) and additional collected data (e.g., thermal data); the tool generated supports decision-making with regard to the introduction of climate-responsive street gardens into the streetscape.

- The identification and incorporation of core elements for climate-change amelioration such as unsealing of road surfaces where appropriate and necessary, integration of decentralized surface-water management systems, and application of high quality, low-maintenance, native planting to promote biodiversity and provide suitable aesthetic value in the urban context. 


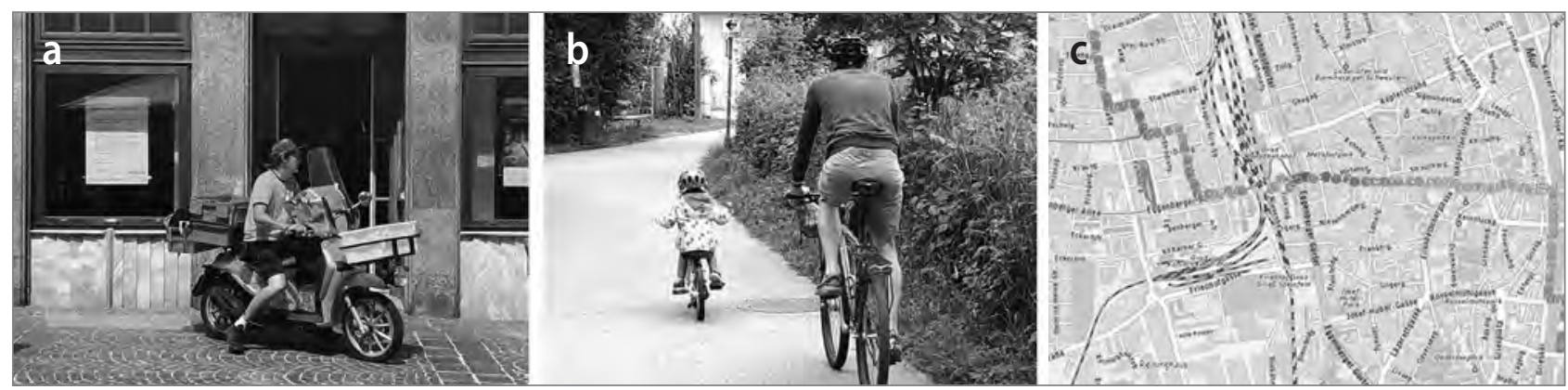

Figure 3: a) NB-loT bike-mounted sensors constitute a mobile network collecting thermal comfort data in the public realm with a continual low-cost data supply; b) NB-IoT sensors can be used for every bicycle; c) 2 to $3{ }^{\circ} \mathrm{C}$ temperature differences as seen on an open road map (dark grey and light grey; source: authors).

Thus, by deliberately unsealing or converting current green areas into climate-responsive street gardens, several functions are covered: cooling, sustainable rainwater management and street drainage, aesthetic and acoustic enhancement, greater acceptance of public spaces, and an increase in biodiversity. Through continuous measurement and evaluation of the measures with specially developed sensor technology with respect to air temperature, humidity, and precipitation values as well as biodiversity audits, the positive effects of climate-responsive street gardens on the immediate environment are also quantitatively verifiable and can be accessed at any time via the specially developed app.

\section{Results}

This section presents the following results:

- Developing suitable sensors and an app to collect and disseminate thermal comfort data;

- Generating a model for developing the GIS-based decision tool;

- Defining a computational approach for incorporating surface-water management;

- Establishing design criteria for appropriate planting design and soils adapted to alternate dry periods and periodic flooding as well as challenging urban conditions (e.g., polluted surface water);

- Securing the pilot implementation of this multifunctional approach in an urban setting; and

- A general plan of areas with pronounced heating and flooding risk and incorporating the plan into urban planning instruments.

\subsection{Developing sensors to collect thermal comfort data}

The approach to developing the sensors examined ways to allow continuous and long-term collection of thermal data. In terms of cost and investment of resources, it was deemed not feasible to install a large network of sensors to collect temperature and humidity. As an alternative, this project proposes implementing a limited number of mobile sensors with GPS trackers, which by their nature can collect data in a wider catchment area. The sensors are to be installed on bikes, either on e-bikes or electric mopeds used by mail carriers, or bike delivery couriers, allowing consistent and wide coverage of city areas. Alternatively, the public could be mobilized to install sensors on their bikes, which would not only provide an additional data source but potentially raise awareness of climate effects (Figure 3).

The current prototype of the mobile sensor collects data for air temperature and humidity, which are important indicators of thermal comfort in urban areas (Fihure 4). A built-in fan allows steady air circulation with the surroundings and increases measuring accuracy. Traditional sensors exposed to direct sunlight supply readings that do not correctly reflect the ambient temperature. Data transfer is carried out using NB-IoT technology via the mobile phone network. NB-IoT was specially developed to deliver data in an energy-saving manner. The battery-operated sensors can therefore continually collect and transfer data over an extended period. Most providers offer this service at a low cost. The first prototypes are already in operation and the data are administrated by a specially designed app (climapp), which can be downloaded onto any smartphone. The results can be viewed on opensource street maps, which show the temperature differential along the street network according to colour (green $=$ cool, red/orange $=$ hot). This approach offers a low-cost alternative to provide a continual and reliable supply of thermal comfort data, which can be used to update the GIS-based assessment tool described above.

\subsection{A GIS-based suitability assessment tool model}

Urban areas are systems with a great deal of inherent complexity that continually evolves as cities grow and densify. Managing 

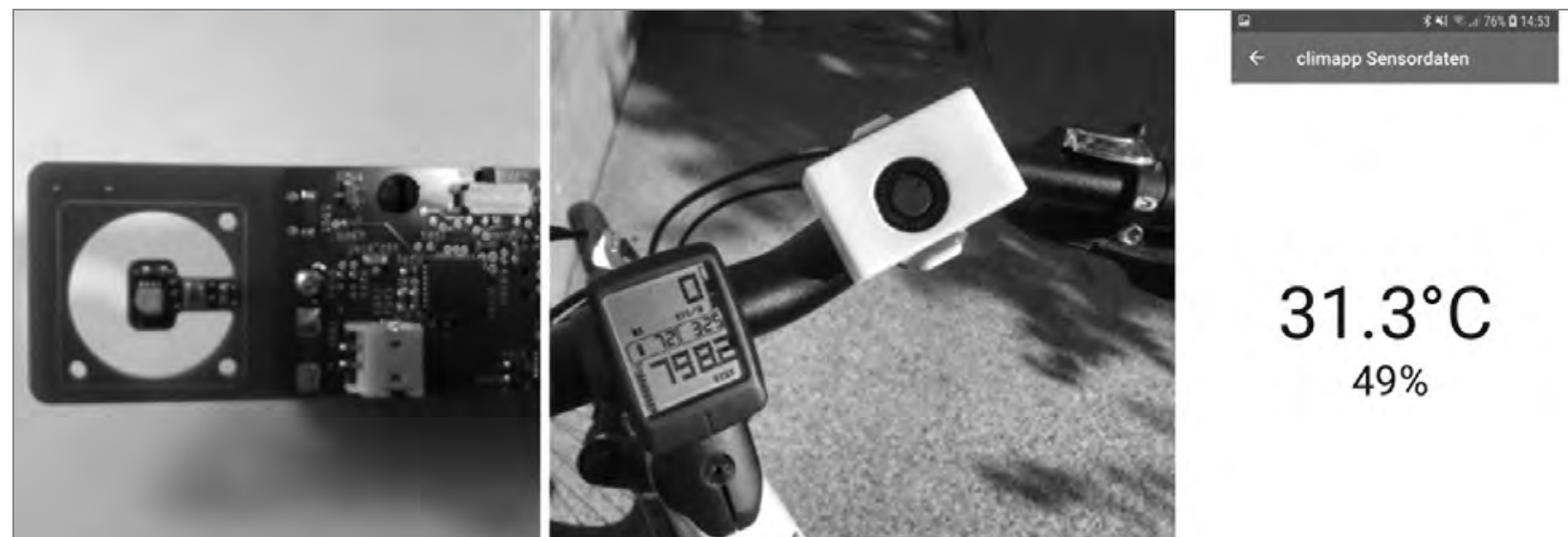

Figure 4: Prototype of the climapp sensor, which collects mobile data on local climate conditions (source: authors).

this complexity has required the adoption of methods that adequately handle spatial information in a stable manner and ensure that this information remains nuanced and is continually updated. This has consequently seen the rise of geographic information systems (GIS), which have specifically been developed to handle the complexity of the spatial data allowing informed decision-making in planning relating to all areas in the urban context. The importance of GIS lies in its ability to pull together vast amounts of information necessary to balance competing priorities and solve problems, such as optimizing the introduction of new green space, as is the intention of this project. The value of this approach has already been recognized as assisting in pinpointing potential locations for rain gardens (Fuskova, 2017).

The simplified schematic diagram (Figure 5) shows the proposed model, which combines current data sets (services plans, aspect ratio, level of impermeability, traffic flows, standards relating to road dimensioning, etc.) and additional thermal comfort data collected by the specially designed mobile sensors. Following the assembly of the relevant data, the implementation of the multi-criteria weighted overlay analysis allows planners to pinpoint areas deemed suitable for introducing green space as a climate-response measure based on specific attributes already selected. This makes it possible to answer the following questions: Where are the measures required? Where are they possible within the context considered? Adopting such an approach would enable planners to make consistent and informed decisions about introducing green space measures based on rational analysis, thereby guaranteeing efficacy, improved return on investment, and increased transparency.

\subsection{Incorporating data for decentralized rainwater management}

The change in the hydrological cycle is one of the key impacts of increasing imperviousness (Shuster et al., 2005). On the one hand, unsealing urban surfaces allows reactivation of the soil as a means of cooling the environment by evapotranspiration to ameliorate UHIs. On the other hand, it directly tackles a further consequence of climate change: reducing or precluding the severe effects of extreme rain events. The assessment of urban hydrological processes differs in some ways from the nature of the remaining input data in the decision system because the effect of rainfall, for example, on the urban system must be computed first. The type of computation significantly depends on the area of interest and its spatial structure as well as on the objective. Although rather simple tools are sufficient for assessing the water balance of an urban area (Sprung et al., 2017), advanced simulation tools are required to assess the temporal and spatial development of urban flooding events (Krebs et al., 2014a). The study objective is also directly correlated with the data demand, and often different assessment approaches in terms of tools must be used for hydrological assessments prior to and after the installation of green infrastructure (Krebs et al., 2013, Krebs et al., 2014b, Leimgruber et al., 2019). After this computational pre-processing, the output produced (e.g., flooding maps) is used as input in the decision tool to identify the optimal locations and soil designs for the climate-responsive street gardens implemented.

\subsection{Selecting appropriate plantings for climate- responsive gardens}

Not all green space is created equal (Wood et al., 2018). The quality and not just the quantity of green space plays a particularly important role in the urban context and in the context of this project. Green infrastructure in cities must comply with several criteria related to the demands of planting in the public realm. These include not just pleasing aesthetics, but also the ability to adapt and remain stable (or attractive) in the face of harsh climate conditions and impacts (e.g., high/low temperatures, traffic, litter, residents, and pets) while at the same time requiring as little maintenance as possible for financially 


\section{1 st analyis phase}

Where are Gl interventions necessary?

- Locate UHI via thermal comfort data

- Assess probability of flash-flooding events
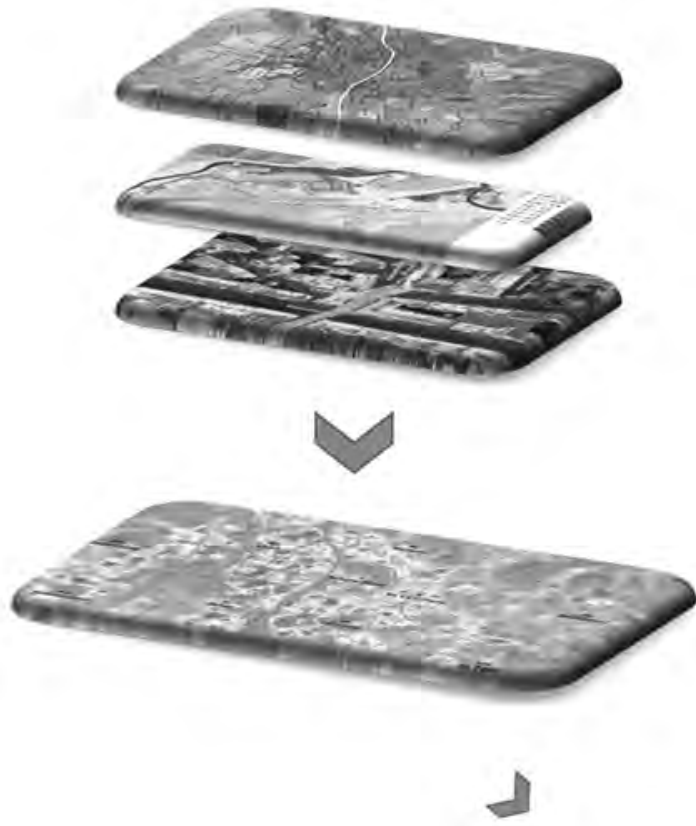

\section{2nd analysis phase}

Where is $\mathrm{Gl}$ technically possible and appropriate?

- Hydrological analysis

- Services location network plan

- Tree and vegetation registry

- Road orientation (N/S)

- Aspect ratio

- Degree of ground-sealing

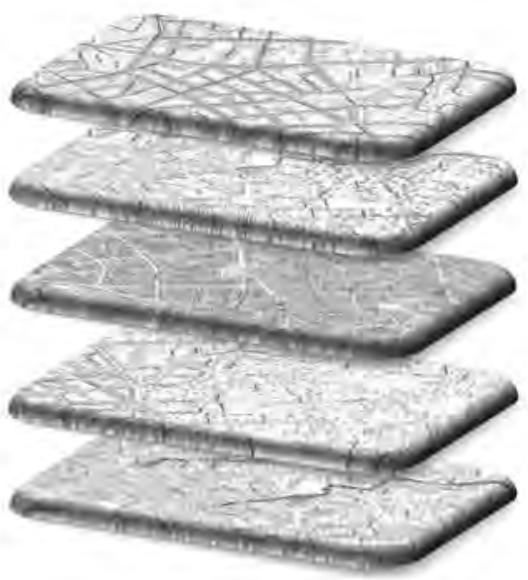

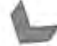

\section{Multi-criteria weighted overlay analysis for site-suitability}
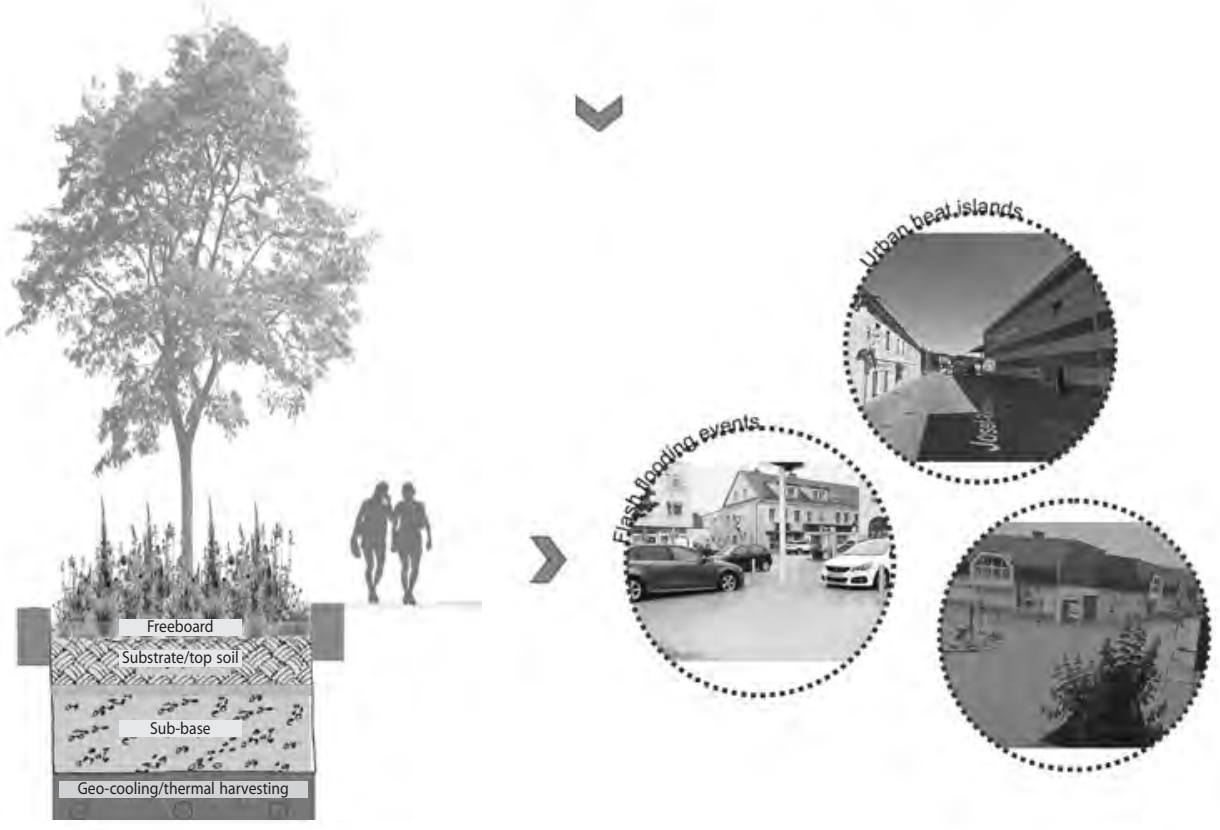

Figure 5: A GIS-based suitability assessment tool for siting multifunctional street gardens in the urban landscape (source: authors). 


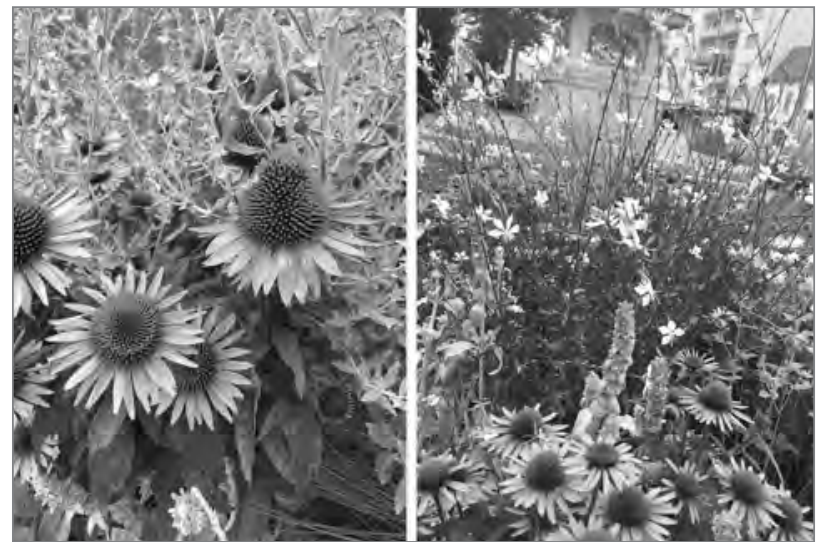

Figure 6: Requirements of contemporary urban planting: high aesthetics, promoting biodiversity, and low maintenance (source: authors).

stretched municipal departments. This is a tall order that in the past has resulted in the prolific use of monoculture planting regimes, which are no longer in keeping with the future requirements of urban green space.

Based on the five-dimensional model presented in Figure 2, the core functions of climate-responsive street gardens for plantings in the urban context are:

- Providing cooling and shade;

- Allowing decentralized management of surface water;

- Increasing biodiversity in urban flora and fauna; and

- Improving health and wellbeing.

Planting regimes that can meet a large part of the core criteria take their inspiration from "gravel gardens", which were first brought to the attention of a wider audience through the work of the British garden designer and horticulturist Beth Chatto (2000). The gravel gardens were an experiment in setting up a garden in one of the driest parts of England with no irrigation and poor, free-draining soil. The resulting spectacular garden display is renowned for containing a rich and attractive drought-tolerant plant species mix that is never watered. The gravel garden technique has been replicated in many gardens throughout the world, and the benefits for planting in the public realm are starting to be recognized (Fallast, 2018; Figure 6). Diverse plant communities in the urban realm are a recurring theme in the work of Hitchmough (2017) and Dunnett (2019), the latter of whom has particularly demonstrated that aesthetics and increased functionality through rain catchment and retention are by no means mutually exclusive. A further development in urban realm planting is demonstrated by Smith (2019) as an attractive low-maintenance alternative to grassed areas where low-level planting is required; the technique incorporates dwarf varieties of chamomile and other species combining horticultural practice with ecology to create a "grass-free lawn" requiring no mowing or fertilizer. Based on a combination of these planting regimes, a planting list was developed that takes account of the core functions and incorporates native varieties where appropriate. The resulting plant list forms the basis for the planting design of climate-responsive street gardens and is to be implemented and monitored in the pilot case studies. The plant list is available from the authors upon request.

The free-draining nature of the engineered ground matrix (50:50 gravel:soil) make this type of planting ideal for use in rainwater management systems (i.e., rain gardens). One of the main benefits of rain gardens with a rich diversity of planting is the ability, as a result of the rooting system, to retain the porous structure of the soil, thereby allowing free drainage through the layers. The self-regulating nature of such planting communities means that this is a low-maintenance and consequently low-cost alternative. The species-rich planting design promotes biodiversity at all levels and provides green space interventions that delight the senses and contribute to health and wellbeing for city dwellers (Figure 7).

\subsection{Pilot application of a climate-responsive street garden system}

This approach is currently being used in the framework of the KLAR (Germ. Klima Anpassungsregionen) research project by klima energie fonds in the municipality of Wolfsberg in Carinthia, Austria. This approach was selected because it corresponds to the aims of the KLAR project: developing and implementing ways to combat the effects of climate change in the urban setting. Based on an interdisciplinary analysis conducted by the CARG working group in the summer of 2020, an area in the immediate vicinity of the main train station in Wolfsberg was identified where this approach could effectively be implemented as a pilot project. Apart from exhibiting a high degree of ground sealing (almost 95\%) and prone to the UHI effect with some of the highest temperatures in the district, the forecourt area has an important function as a mobility hub and commercial district that will take on increased significance when the Koralm Railway link is put into operation in 2025. The implementation is planned for 2021.

A network of stationary sensors will be installed to monitor the thermal comfort situation before implementation of the measures and post-implementation. The pilot phase relies on activating existing green space by converting the area directly in front of the train station entrance into a rain garden measuring approximately $200 \mathrm{~m}^{2}$. The area that has been designated as the rain garden will undergo some modification to allow surface water to drain into the engineered soil. The monoculture planting is to be replaced with a perennial/grass mix of appropriate native species to withstand dry conditions 


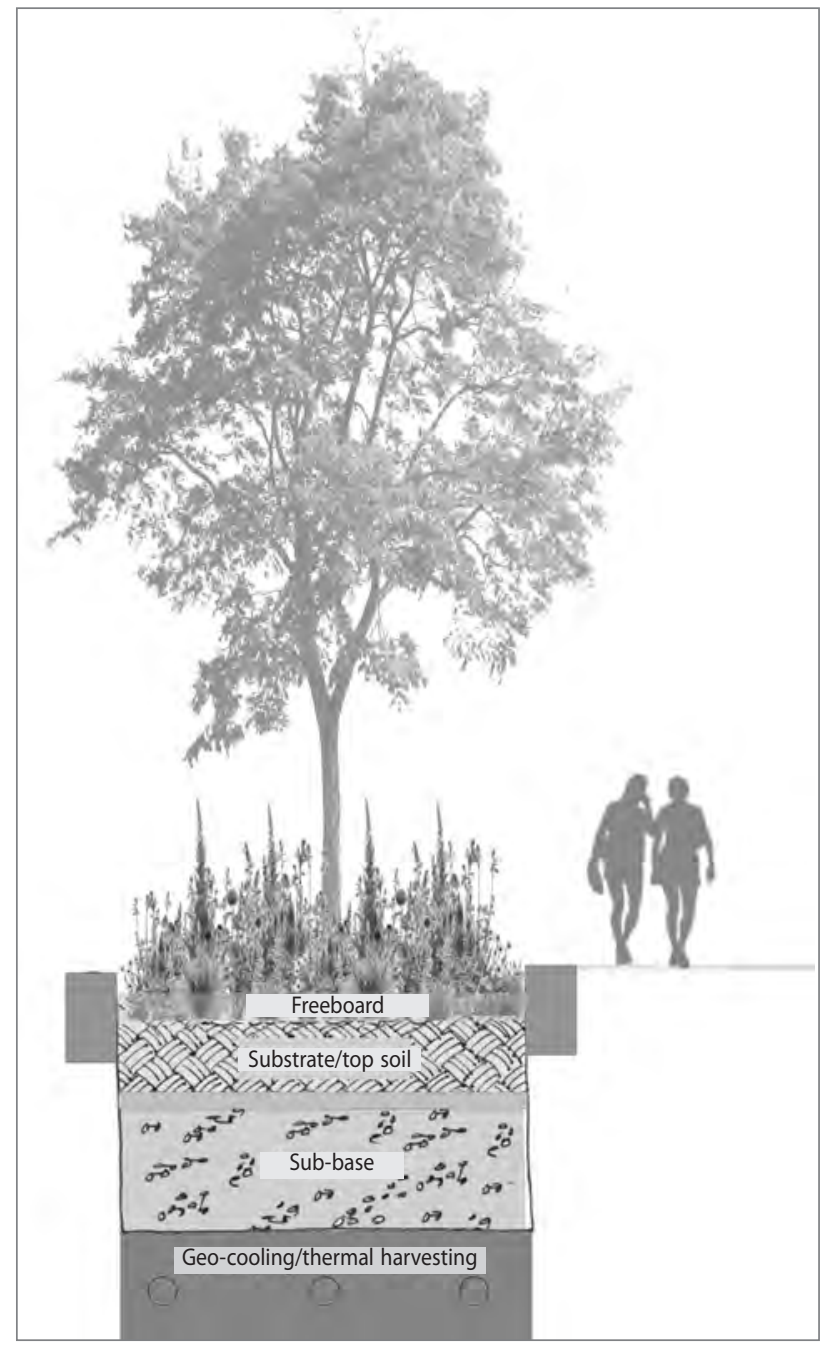

Figure 7: Gravel gardens provide free-draining ground conditions suitable for the quick uptake of surface water (source: authors).

and periodic flooding. The aim is to maintain an acceptable aesthetic while promoting maximum biodiversity in the urban context. If the GI intervention proves successful, it will be extended to other areas. The effects (reduction of temperature and public acceptance for new planting) will be monitored during the project duration.

\section{Discussion and next steps}

The pilot results represent the first steps in the development of this approach and form a solid basis for further advancement. Clearly there remains a significant amount of work to be done in developing a system that is more widely applicable. The envisaged next steps are also discussed in this section.

The sensors may be used as a stationary unit or as a mobile unit. A mobile unit offers the greatest flexibility in terms of low-cost continuous thermal comfort data collection in com- parison to current methods using aerial images from aircraft or drone-mounted cameras (Soto-Estrada et al., 2017). The main advantage of the system presented is a continuous supply of data, which allows a more comprehensive picture of the situation with respect to changing ambient conditions over time. It has been found that the need to mount an extra device onto a bike presents an obstacle to widespread adoption. An additional disadvantage is that the module is currently not weatherproof, which precludes a permanent fixture. Future development is therefore focussing on incorporating the sensor into current bike accessories (such as the bike bell) or integrating it into the bike frame itself. Some loss of data was experienced when the battery charge was low. It is therefore also planned to produce a module powered by solar cells, allowing for continuous off-grid application. An application for grant funding for this development has been submitted to the Styrian government (SFG, Steirische Forschungsgesellschaft) and is currently under review. The data can currently be viewed on open-source streets maps. A higher degree of accuracy in terms of being able to zoom in on the streetscape to determine precisely where the measurements originated will be the next development step, requiring a refined information-design approach.

The basic model for the GIS-based decision tool has been established and will be implemented as the next step. The challenge lies in putting together the heterogeneous data sets from the various stakeholders into a coherent model. The thermal comfort data collected via the mobile and stationary sensors does not present this problem, and these data may be adapted at the source to suit the requirements of the tool.

The standardized planting regime was selected based on requirements related to aesthetics, biodiversity, robustness, and knowledge about low-maintenance planting regimes for gravel gardens and rain-garden technology. Field testing the planting communities is the next stage for ascertaining suitability for their function in the urban street setting. The field testing will be carried out over two to three seasons to allow the planting to establish itself. Factors to be assessed include behaviour with respect to prolonged periods of high temperatures and reduced precipitation, the frequency of the requirement for intervention to maintain the planting feature, reaction to surface-water contamination from winter de-icing and traffic pollution, rating of attractiveness, and corresponding public acceptance. An ecological audit is also planned to establish the effects on the level of biodiversity in this area (i.e., the variety and numbers of pollinating insects). The results will be used to optimize the planting regime accordingly.

State-of-the-art hydrologic-hydrodynamic simulation tools allow the design and evaluation of decentralized nature-based 

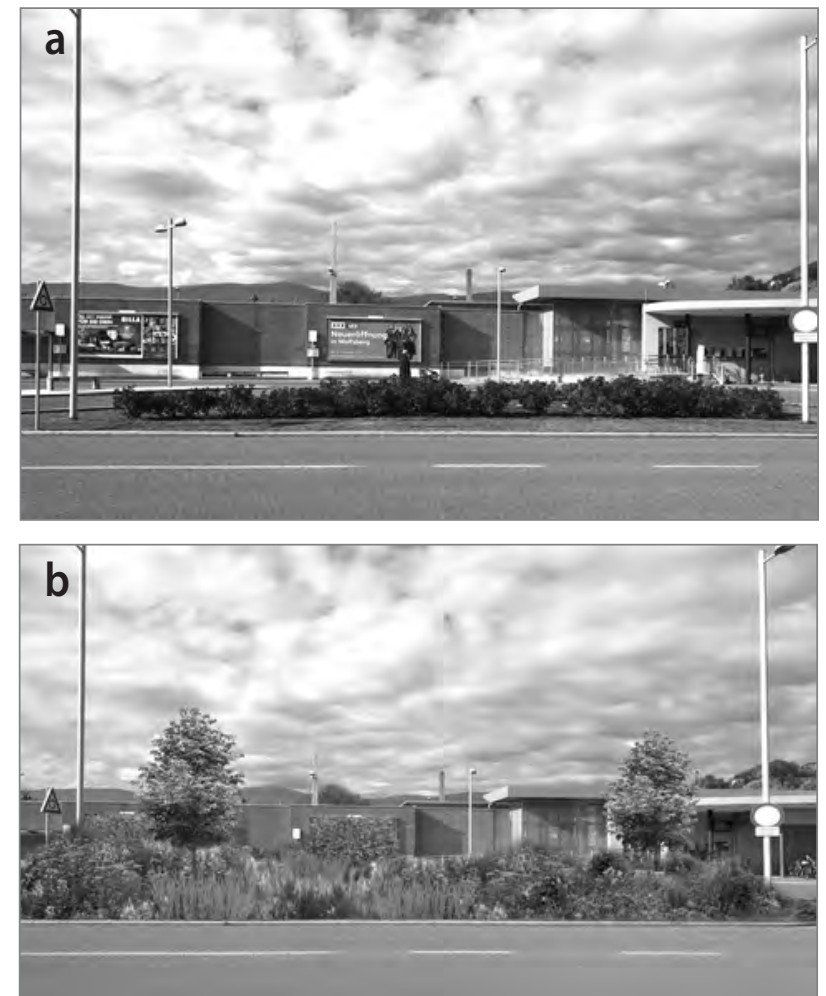

Figure 8: (a) Forecourt of the main railway station in Wolfsberg, (b) Visualization of the forecourt as multifunctional climate-responsive street gardens (source: authors).

stormwater management strategies at various urban scales ranging from small rain gardens to a city-scale strategy. An important aspect is the increasing availability of data, both spatial and hydro-meteorological data, which supports a realistic evaluation of the effectiveness and performance of stormwater management strategies. Thus, hydrologic-hydrodynamic simulation results have provided crucial input for the GIS-based decision tool.

The pilot implementation in the small city of Wolfsberg defined for the first time the term climate-responsive street gardens as a move toward incorporating a much wider functionality than is found in most current urban green infrastructure in direct response to the diverse challenges to city life caused by climate change. It is therefore appropriate to extend the meaning of garden to include not only visible planting as an aesthetic and cooling element, but also the unseen contribution of subterranean layers, which are specifically engineered to serve a variety of important functions in the urban environment. In addition, climate-responsive street gardens are also an invitation to the public to consider the true value of green infrastructure in terms of ensuring continued biodiversity and the wellbeing of body and mind for the foreseeable future. They are a truly urban "green machine" (Wallace, 1990) at all levels.
An important aspect of the monitoring process following implementation is to establish the level of public acceptance of this type of multifunctional green infrastructure and to ascertain whether the additional functionality that directly addresses climate adaptation could play a role in gaining increased public support. It is considered that the implementation of the climate-responsive street garden approach generates added value to various aspects of present and future urban life. Based on integrated green infrastructure planning principles (Monteiro et al., 2020), the approach allows optimal and sustainable use of resources such as space and water by relieving urban wastewater systems, resulting in reduced direct costs and protection of natural watercourses. It offers a self-regulating, low-maintenance version for climate amelioration while potentially increasing urban biodiversity using site-consistent and species-rich planting (Mody et al., 2020). The spatial reconfiguration of the street space through the inclusion of GI in this form has the potential to promote psychological wellbeing according to the principles of horticultural therapy when applied to the public realm (Ulrich, 1984; Kaplan \& Kaplan, 1989) and may encourage increased active mobility (walking and cycling) by offering more attractive routes created by the new greenery (Fallast, 2017; Dunnett, 2019). In addition, it offers identity-creating activation of public space (Pansinger, 2019).

This approach also seeks to demonstrate that it is not always large projects in big cities that are required. Often it is small acupuncture-like measures that can bring about important changes and innovations (Figure 9).

\section{Conclusion}

Multifunctional climate-responsive street gardens are primarily intended for implementation in the streetscape (i.e., the public realm). In the pilot phase, it is intended to specifically target areas in the road that are asphalted but closed to motorized transport (i.e., "dead" zones with no specific traffic function) for retrofitting to facilitate acceptance by the general public. An important part of the process is also about raising awareness that road space should not only be understood as a traffic connection, but that the street should be perceived and used as a public space and as a fundamental asset for urban ecosystems.

The approach presented therefore aims to innovate by developing a systematic procedure for implementing green interventions in the urban public realm by applying:

- A GIS-based suitability assessment tool that brings together all relevant data required to make decisions about the location and type of green intervention;

- A multifunctional approach and interdisciplinary and transdisciplinary method to implement measures to combat climate change; 
- Mobile sensor technology with GPS tracking to gather microclimate data subsequently employed by the suitability assessment tool, which allows low-cost and continued monitoring of dynamic urban microclimates, setting itself apart from the current ad hoc approach to introducing green space into the urban context as a means of combating the effects of climate change; and

- A flexible system that caters to the requirements of an established urban fabric, which is often subject to strict planning regulations and restricted by space, and offers flexible but effective green space interventions ("green acupuncture"), which can positively influence local climate conditions in a sustainable manner.

Multifunctional climate-responsive street gardens are a smallscale transferable measure. This approach rethinks colours, textures, depths, and functionality, thereby reshaping elements such as heat, rain, dust, and noise in urban areas into the "new shape of green".

Marie Therese Fallast, PLANUM Fallast \& Partner GmbH, Graz, Austria E-mail:mt.fallast@planum.eu

Sanela Pansinger, Adasca, Graz, Austria

E-mail: sanela.pansinger@adasca.org

Gerald Krebs, University of Technology, Institute of Hydraulic Engineering and Water Resources Management, Graz, Austria E-mail: gerald.krebs@tugraz.at

Martin Moser, Quadratic GmbH, Graz, Austria

E-mail:martin.moser@quadratic.at

Andreas Zobl, Quadratic GmbH, Graz, Austria

E-mail:andreas.zobl@quadratic.at

\section{References}

Chatto, B. (2000) Drought-resistant planting - Lessons from Beth Chatto's gravel garden. London, Francis Lincoln.

Christiaanse, K. (2018) Collected text on the built environment 1990-2018. Rotterdam, NAI010 Publishers.

Dunnett, N. (2019) Naturalistic planting design - The essential guide. Bath, Filbert Press.

Fallast, M. T. \& Fallast, K. (2017) Active mobility as part of a sustainable mobility masterplan. Towards a humane city VI. Research report. Novi Sad, Faculty of Technical Sciences.

Fallast, M. T. (2018) Category 3: urban gardening - Creative gardening in the city. Available at: https://www.naturimgarten.at/files/content/3.\%20 VERANSTALTUNGEN/DIV/Award/Kategorie\%203\%20PDFs/3\%20Marie-Therese\%20Fallast\%20EN.pdf (accessed 2 Dec. 2020).

Fuskova, V., Stepankova, R. \& Fuska, J. (2017) GIS analysis of potential locations for rain gardens in village Alekšince. Paper presented at Conference MendelNet 2017, 8-9 November, Brno. Typescript.

Gehl, J. (2015) City for people. Berlin, Jovis Verlag.
Hitchmough, J. (2017) Sowing beauty: Designing flowering meadows from seed. Portland, OR, Timber Press.

IPBES (2019) Global assessment report on biodiversity and ecosystem services of the Intergovernmental Science-Policy Platform on Biodiversity and Ecosystem Services. Bonn, IPBES Secretary.

Internet 1: https://livingroofs.org/graz-green-infrastructure/ (accessed 22 Feb. 2021).

Internet 2: https://www.georgetownclimate.org/adaptation/toolkits/green-infrastructure-toolkit/implementing-pilots-best-practices-and-tools.html (accessed 21 Feb. 2021).

Isbell, F., Adler, P. R., Eisenhauer, N., Fornara, D., Kimmel, K., Kremen, C., et al. (2017) Benefits of increasing plant diversity in sustainable agroecosystems. Journal of Ecology, 105, pp. 871-879.

DOI: $10.1111 / 1365-2745.12789$

Kaplan, R. \& Kaplan, S. (1989) The experience of nature: A psychological perspective. Cambridge, Cambridge University Press.

Kaynakli, O. (2011) Parametric investigation of optimum thermal insulation thickness for external walls. Energies, 4(12), pp. 913-927. DOI: 10.3390/en4060913

Koc, C. B., Osmond, P. \& Peters, A. (2018) Evaluating the cooling effects of green infrastructure: A systematic review of methods, indicators and data sources. Solar Energy, 166, pp. 486-508.

DOI: 10.1016/j.solener.2018.03.008

Kozamernik, J., Rakuša, M. \& Nikšič, M. (2020) How green facades affect the perception of urban ambiences: Comparing Slovenia and the Netherlands. Urbani izziv, 31(2), pp. 88-100.

DOI: 10.5379/urbani-izziv-en-2020-31-02-003

Krebs, G., Kokkonen, T., Valtanen, M., Koivusalo, H. \& Setälä, H. (2013) A high-resolution application of a stormwater management model (SWMM) using genetic parameter optimization. Urban Water Journal, 10(6), pp. 394-410. DOI: 10.1080/1573062X.2012.739631

Krebs, G., Kokkonen, T., Valtanen, M., Setälä, H. \& Koivusalo, H. (2014a) Spatial resolution considerations for urban hydrological modelling. Journal of Hydrology, 512, pp. 482-497.

DOI: 10.1016/j.jhydrol.2014.03.013

Krebs, G., Kokkonen, T., Valtanen, M. \& Koivusalo, H. (2014b) Large-scale urban hydrological modelling at high spatial resolution: requirements and applications. In: Marchettini, N., Brebbia, C. A., Pulselli, R. \& Bastianoni, S. (eds.) The sustainable city IX, pp. 1593-1603. Southampton, UK, WIT Press. DOI: 10.2495/SC141352

Kristl, Ž., Senior, C. \& Temeljotov Salaj, A. (2020) Key challenges of climate change adaptation in the building sector. Urbani izziv, 31(1), pp. 101-111. DOI: 10.5379/urbani-izziv-en-2020-31-01-004

Leimgruber, J., Krebs, G., Camhy, D. \& Muschalla, D. (2019) Model-based selection of cost-effective low impact development strategies to control water balance. Sustainability, 11(8), 2440. DOI: 10.3390/su11082440

Manso, M. \& Castro-Gomes, J. P. (2015) Green wall systems: A review of their characteristics. Renewable and Sustainable Energy Reviews, 41, pp. 863-871. DOI:10.1016/j.rser.2014.07.203

Markvica, K., Millonig, A., Leodolter, M. \& Haufe, N. (2020) Promoting active mobility behavior by addressing information target groups: The case of Austria. Journal of Transport Geography, 83, 102664. DOI: 10.1016/j.jtrangeo.2020.102664

Mody, K., Lerch, D., Müller, A. K., Simons, N. K., Blüthgen, N. \& Harnisch, M. (2020) Flower power in the city: Replacing roadside shrubs by wildflower meadows increases insect numbers and reduces maintenance costs. PLOS One, 15(6). DOI: 10.1371/journal.pone.0234327 
Monteiro, R., Ferreira, J. C. \& Antunes, P. (2020) Green infrastructure planning principles: An integrated literature review. Land, 9, 525. DOI: 10.3390/land9120525

Pansinger, S. (2018) How much density do we really need? Part I. In: Petersson, P., Kickenweitz, P., Linortner, C. \& Krejs, B. (eds) Intensified density - A small scape densification strategy with using modular construction, pp. 44-49. Graz, Verlag der Technischen Universität Graz.

Pansinger, S. (2019) World heritage and gestalt sustainability. ISG Magazin, 2, pp. 26-30.

Pansinger, S., Förster, J. (2018) Airport neighborhood as future regional development areas for resource awareness and gestalt sustainability. In: Brebbia, C. A., Marchettini, N. \& Passerini, G. (eds.) WIT transactions on ecology and the environment: Sustainable development and planning $X$, pp. 259-268. Southampton, UK, WIT Press. DOI: 10.2495/SDP180241

Shuster, W. D., Bonta, J., Thurston, H., Warnemuende, E. \& Smith, D. R. (2005) Impacts of impervious surface on watershed hydrology: A review. Urban Water Journal, 2(4), pp. 263-275. DOI: 10.1080/15730620500386529

Smith, L. (2019) Tapestry lawns: Freed from grass and full of flowers. Boca Raton, FL, CRC Press. DOI: 10.1201/9780429263217

Soto-Estrada, E., Correa-Echeverri, S. \& Posada-Posada, M. I. (2017) Thermal analysis of urban environments in Medellin, Colombia, using an unmanned aerial vehicle (UAV). Journal of Urban and Environmental Engineering, 11(2), pp. 142-149. DOI: 10.4090/juee.2017.v11n2.142149

Sprung, W., Krebs, G., Beutle, K. \& Muschalla, D. (2017) Maßnahmenkarte zur grundwasseranreicherung Stadt Graz. Graz, Aqua Urbanica.

Ulrich, R. S. (1984) View through a window may influence recovery from surgery. Science, New Series, 224(4647), pp. 420-421.

DOI: $10.1126 /$ science.6143402

Wallace, A. (1990) The green machine: Ecology and the balance of nature. Oxford, Blackwell.

Willenbrock, H. (2020) Die gestresste Stadt. Available at: https://www. brandeins.de/magazine/brand-eins-wirtschaftsmagazin/2020/wie-wollen-wir-leben/die-gestresste-stadt (accessed 21 Feb. 2021).

Wood, E., Harsant, A., Dallimer, M., Cronin de Chavez, A., McEachan, R. R. C. \& Hassall, C. (2018) Not all green space is created equal: Biodiversity predicts psychological restorative benefits from urban green space. Frontiers in Psychology, 9. DOI: 10.3389/fpsyg.2018.02320

Xuexiu, Z., Yanwen, L. \& Jiang, H. (2020) Analysis of the thermal environment in pedestrian space using 3D thermal imaging. Energies, 13(14), 3674. DOI: 10.3390/en13143674 